\title{
Body Posture Asymmetry in Prematurely Born Children at Six Years of Age
}

\author{
Katarzyna Walicka-Cupryś, ${ }^{1,2}$ Justyna Drzał-Grabiec, ${ }^{1,2}$ Maciej Rachwal, ${ }^{1,2}$ \\ Paweł Piwoński, ${ }^{1,2}$ Lidia Perenc, ${ }^{1,2}$ Lukasz Przygoda, ${ }^{1,2}$ and Katarzyna Zajkiewicz ${ }^{1,2}$ \\ ${ }^{1}$ Medical Faculty, Institute of Physiotherapy, University of Rzeszow, Rejtana 16c, 35-959 Rzeszów, Poland \\ ${ }^{2}$ Centre for Innovative Research in Medical and Natural Sciences, Medical Faculty, University of Rzeszow, Warzywna 1a, \\ 35-310 Rzeszów, Poland
}

Correspondence should be addressed to Katarzyna Walicka-Cupryś; kwcuprys@o2.pl

Received 17 June 2017; Accepted 13 September 2017; Published 18 October 2017

Academic Editor: Jonathan Muraskas

Copyright (C) 2017 Katarzyna Walicka-Cupryś et al. This is an open access article distributed under the Creative Commons Attribution License, which permits unrestricted use, distribution, and reproduction in any medium, provided the original work is properly cited.

\begin{abstract}
Aims. The purpose of the study was to assess body posture asymmetries in the standing and sitting position in prematurely born children at six years of age. Study Design and Subjects. We measured trunk symmetry in coronal plane. The study was carried out in a group of 101 children, aged 6-7 years, mean age of 6.63, including 50 preterm children born at gestational age $<32$ weeks (preterm group) and 51 full-term children (control group). Outcome Measures. Trunk symmetry in coronal plane was measured using photogrammetric technique with Mora 4G CQ Elektronik. The subjects were examined in standing and sitting position. Statistical analyses were carried out using Shapiro-Wilk $W$-test, Student's $t$-test, Mann-Whitney $U$ test, and Pearson's chi-squared test. Statistical significance was assumed at $p<0.05$. Results. No significant differences were found between the groups in the asymmetries identified in the relevant anthropometric points, relative to the position assumed during the examination or to the subjects' sex. Conclusions. There are no significant differences in body posture in the coronal plane, between preterm children and full-term children. Premature birth does not have adverse effects related to body posture asymmetry in preterm children at the age of six.
\end{abstract}

\section{Introduction}

Due to advances in perinatal and neonatal care, survival rates for preterm infants have increased [1]; however, the risk of neurodevelopmental impairment remains high [2].

Neonatal posture requires a number of active postural control mechanisms, that is, neuromotor functions, which allow controlling its body posture at rest, during displacement and during active movements [3]. Postural control is intimately linked to motor control: dynamic motor actions cannot be performed without first stabilising body posture [4].

The third trimester in the uterus, which is missed in part or in whole by premature infants, promotes the ideal, flexed position when the infant is crowded by the uterine environment and experiences rapid brain growth, mediating flexion (arms and legs bent and trunk tucked forward), and midline orientation [5]. Positioning in physiological flexion (flexion of the shoulders, hips, and knees, scapular protraction, and posterior pelvic tilt) is the ideal position of the newborn, as it promotes proper joint alignment and symmetry, supports neuromuscular development, and promotes self-soothing and behavioural organization [6]. However, premature infants lack tonal responses and strength at birth, and they often assume extended (straight) positioning of the neck, back, and extremities [7]. Extended positioning can affect acquisition of developmental motor skills and hinder self-regulation [8] and may interfere with oral feeding skills. One study found that children born preterm were more likely to demonstrate extension in the trunk which interfered with sitting posture and significantly influenced mobility, promoted asymmetry, and decreased hand function at 1 year of age [9]. Most studies into body asymmetry in preterm children focus on the period of infancy, yet there 
TABLE 1: Anthropometric parameters in the cohort.

\begin{tabular}{|c|c|c|c|c|c|c|c|c|}
\hline \multirow[t]{2}{*}{ Variables } & \multicolumn{3}{|c|}{$\begin{array}{l}\text { Preterm group } \\
(n=50)\end{array}$} & \multicolumn{3}{|c|}{$\begin{array}{l}\text { Control group } \\
(n=51)\end{array}$} & \multirow[t]{2}{*}{$Z$} & \multirow[t]{2}{*}{$p$} \\
\hline & $\bar{x}$ & $\mathrm{Me}$ & $\mathrm{SD}$ & $\bar{x}$ & $\mathrm{Me}$ & $\mathrm{SD}$ & & \\
\hline Body height & 116.52 & 115.50 & 8.02 & 118.98 & 118.00 & 7.91 & -1.82 & 0.069 \\
\hline Body weight & 21.11 & 19.90 & 4.78 & 23.12 & 21.90 & 4.74 & -2.57 & 0.010 \\
\hline BMI & 15.40 & 15.11 & 2.05 & 16.20 & 15.80 & 1.94 & -2.35 & 0.019 \\
\hline
\end{tabular}

$n$ : number of observations; $\bar{x}$ : arithmetic mean; Me: median; SD: standard deviation.

are no research reports discussing the related effects in the development of body posture in older children.

The aim of our study was designed to assess body posture asymmetries in the standing and sitting position in prematurely born children at six years of age.

\section{Methods}

2.1. Participants. The study examined a group of 101 children, aged 6-7 years, mean age of 6.63, including 50 preterm children: 25 boys and 25 girls (preterm group) and 51 fullterm children: 22 boys and 29 girls (control group). Children with neurologic or orthopaedic disorders affecting the ability to assume vertical posture without assistance were excluded from the study. The following criteria for including into the study group were adopted: guardians' and children's consent for participation, birth before gestational age of 32 weeks, and lack of neurologic and orthopaedic disorders affecting body posture. Inclusion criteria for the controls were as follows: guardians' and children's consent for participation, lack of neurologic and orthopaedic disorders affecting body posture, age matching that of the study group, and birth at gestational age after 36 and before 42 weeks. The study was conducted in 2016, in south-eastern Poland, at the Centre for Innovative Research in Medical and Natural Sciences operating at the University of Rzeszów.

2.2. Anthropometric Measurements. All the measurements were performed on the same day, starting with anthropometric measurements. Body height was measured with Seca 213 mobile stadiometer, with an accuracy of $0.1 \mathrm{~cm}$. Body mass was measured using electronic scale OMRON BF 500, with an accuracy of $0.1 \mathrm{~kg}$. The measurements were performed in standard conditions; children in underwear and barefoot were standing in upright position, without bending knees. Anthropometric measures of both groups are shown in Table 1.

2.3. Body Posture Measurements. Body posture was examined using photogrammetry technique based on projection moiré phenomenon, Mora 4G CQ Elektronik [10].

Research has confirmed that results obtained by photogrammetric method are very close to X-ray outcomes [11, 12] and reproducible [13].

Before the measurement, anthropometric points, used later to calculate the relevant parameters, were marked on each subject's body. The anthropometric points were determined by palpation by a physiotherapist with 10 years of experience and extensive practice in photogrammetric measurements. Following the palpation of the points (spinous processes, lower corners of the scapulae, peak of kyphosis, the deepest point of lordosis, transition of kyphosis into lordosis, and posterior iliac spines), they were marked with a dermatograph, the procedure being consistent with other similar studies [14-17]. The image was recorded after marking all the essential points and positioning the subject with his or her back to the camera, in habitual standing posture with straight knees and gaze oriented forward. The computer registered around a dozen images. During the next recording of spinal curvatures the subject was sitting on a stool, with feet against the floor, in an unrestrained position, without spine adjustments, with gaze oriented forward. This assessment was performed because the sitting posture is a preferred position for examining the rib or loin hump during school screening as it demonstrates the best correlation with the spinal deformity exposing the real trunk asymmetry [18]. Then, the image capturing correct positioning of the subject, in the habitual position without twisting of the trunk or pelvis, was selected, and the anthropometric points were transferred onto a photogram on the computer screen. Based on the marked points, the computer defined the parameters describing the body posture by assessing the distance of the selected points from the camera.

The subject is positioned at a distance of $2.6 \mathrm{~m}$ from the camera while the device projects lines of strictly defined parameters onto his/her back, allowing a spatial image to be obtained. These lines reach the subject's back at a specific angle and are distorted depending on the distance of a given point from the device. The computer records line image distortions, and numerical algorithms are used to convert these into a contour map of the surface. In optics, the physical basis of this method is called the moiré phenomenon [19].

We analysed the parameters presented in Figure 1:

CIT [degree]: coronal inclination of the trunk;

DHS [mm]: difference in the height of shoulders;

DHCS [mm]: difference in the height of the lower corners of the scapulae;

DDCS [mm]: difference in the distances from the lower corners of the scapulae to the spine;

DHP [mm]: difference in the height of the pelvis;

$\mathrm{SA}[\mathrm{mm}]$ : maximum deflection of the line connecting the spinous processes from C7-S1 line. 


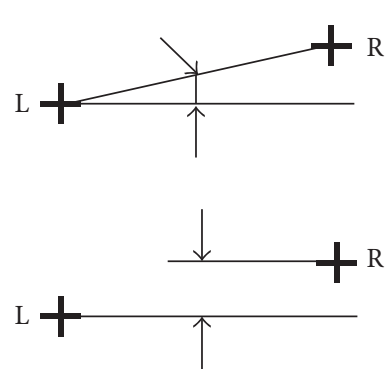

(a)

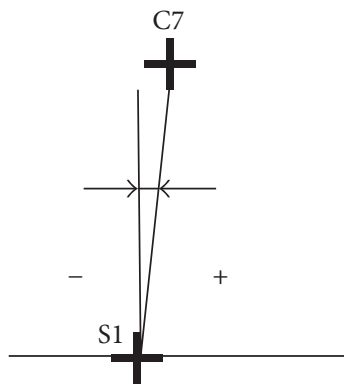

(b)

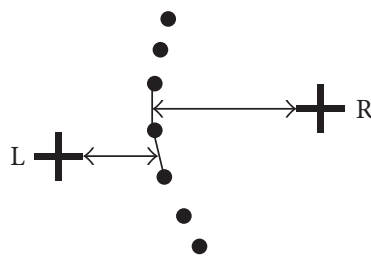

(c)

Figure 1: A method of determining the following parameters: (a) differences in the height of shoulders, scapulae and pelvis; (b) coronal inclination of the trunk; (c) difference in distances from the lower corners of the scapulae to the spine.

TABLE 2: Body posture parameters in standing and in sitting position, relative to gestational age at birth.

\begin{tabular}{|c|c|c|c|c|c|c|c|c|}
\hline \multirow[t]{2}{*}{ Variables } & \multicolumn{3}{|c|}{$\begin{array}{l}\text { Preterm group } \\
(n=50)\end{array}$} & \multicolumn{3}{|c|}{$\begin{array}{l}\text { Control group } \\
(n=51)\end{array}$} & \multirow[t]{2}{*}{$t / Z$} & \multirow[t]{2}{*}{$p$} \\
\hline & $\bar{x}$ & $\mathrm{Me}$ & SD & $\bar{x}$ & $\mathrm{Me}$ & $\mathrm{SD}$ & & \\
\hline \multicolumn{9}{|c|}{ Standing position } \\
\hline CIT [degree] & 1.26 & 0.95 & 0.91 & 1.18 & 1.10 & 0.82 & 0.16 & 0.876 \\
\hline DHS [mm] & 7.17 & 5.60 & 5.40 & 5.66 & 5.00 & 4.60 & 1.30 & 0.194 \\
\hline DHCS [mm] & 5.40 & 5.05 & 3.71 & 5.57 & 4.50 & 4.88 & 0.36 & 0.721 \\
\hline DDCS [mm] & 5.18 & 4.50 & 4.36 & 5.10 & 3.90 & 4.65 & 0.36 & 0.721 \\
\hline $\mathrm{DHP}[\mathrm{mm}]$ & 2.50 & 2.20 & 2.02 & 2.84 & 2.80 & 2.26 & -0.71 & 0.480 \\
\hline AS $[\mathrm{mm}]$ & 5.43 & 4.95 & 2.63 & 5.38 & 4.50 & 3.23 & 0.61 & 0.541 \\
\hline \multicolumn{9}{|c|}{ Sitting position } \\
\hline CIT [degree] & 1.64 & 1.60 & 1.12 & 1.59 & 1.50 & 1.17 & 0.34 & 0.734 \\
\hline DHS [mm] & 5.54 & 4.50 & 5.43 & 6.51 & 5.00 & 5.75 & -0.91 & 0.365 \\
\hline DHCS [mm] & 5.27 & 4.50 & 3.89 & 4.93 & 4.50 & 4.29 & 0.67 & 0.505 \\
\hline DDCS [mm] & 6.34 & 5.10 & 5.05 & 7.88 & 6.80 & 5.71 & -1.32 & 0.185 \\
\hline $\mathrm{DHP}[\mathrm{mm}]$ & 2.79 & 2.20 & 2.44 & 3.79 & 3.30 & 3.31 & -1.37 & 0.172 \\
\hline AS $[\mathrm{mm}]$ & 6.94 & 6.50 & 3.03 & 7.02 & 6.30 & 4.18 & 0.49 & 0.621 \\
\hline
\end{tabular}

$n$ : number of observations; $\bar{x}$ : arithmetic mean; Me: median; SD: standard deviation; $t$ : result of Student's $t$-test for independent variables; $Z$ : result of Mann-Whitney $U$ test; $p$ : level of probability; CIT [degree]: coronal inclination of the trunk; DHS [mm]: difference in the heights of shoulders; DHCS [mm]: difference in the heights of the lower corners of the scapulae; DDCS [mm]: difference in the distances from the lower corners of the scapulae to the spine; DHP $[\mathrm{mm}]$ : difference in the height of the pelvis; SA [mm]: maximum deflection of the line connecting the spinous processes from C7-S1 line.

2.4. Statistics. Statistical analyses of the collected material were performed using Statistica 10.0 from StatSoft. Both parametric and nonparametric tests were applied in the analysis of the variables. The choice of parametric test depended on the fulfilment of its basic assumptions, that is, conformity of the distributions of the examined variables with normal distribution, which was verified with ShapiroWilk $W$-test. Descriptive statistics, calculated for all numerical variables, included the mean, median, and standard deviation. Assessment of differences in the average value of a numerical characteristic in the two populations was performed with Student's $t$-test for independent variables, or alternatively, with nonparametric Mann-Whitney $U$ test. Analysis of qualitative data was carried out using Pearson's chi-squared test. Statistical significance was assumed at $p<$ 0.05 .
2.5. Ethics. The study was approved by Bioethics commission at the Faculty of Medicine, University of Rzeszów, Poland. The children's parents gave their written informed consent to their children' participation in the study.

\section{Results}

Calculations were performed to determine coronal plane parameters of trunk posture and their possible asymmetries in preterm and full-term children at the age of 6 years.

Analyses of body posture parameters related to asymmetries in trunk inclination, position of the shoulders, position of the scapulae and their distance from the spine, position of the pelvis, and shape of the spine in the coronal plane have shown no significant differences between the group of preterm children and the group of full-term children, regardless of the assumed posture (Table 2). 
TABLE 3: Body posture parameters in standing and in sitting position, relative to gestational age at birth, in girls.

\begin{tabular}{|c|c|c|c|c|c|c|c|c|}
\hline \multirow[t]{2}{*}{ Variables } & \multicolumn{3}{|c|}{$\begin{array}{c}\text { Girls } \\
\text { preterm group }(n=25)\end{array}$} & \multicolumn{3}{|c|}{$\begin{array}{c}\text { Girls } \\
\text { control group }(n=29)\end{array}$} & \multirow[t]{2}{*}{$t / Z$} & \multirow[t]{2}{*}{$p$} \\
\hline & $\bar{x}$ & $\mathrm{Me}$ & $\mathrm{SD}$ & $\bar{x}$ & $\mathrm{Me}$ & $\mathrm{SD}$ & & \\
\hline \multicolumn{9}{|c|}{ Standing position } \\
\hline CIT [degree] & 1.27 & 1.10 & 0.86 & 0.99 & 1.00 & 0.77 & 1.20 & 0.230 \\
\hline DHS [mm] & 6.16 & 4.50 & 5.58 & 4.67 & 2.80 & 4.18 & 0.97 & 0.330 \\
\hline DHCS $[\mathrm{mm}]$ & 5.55 & 5.60 & 3.77 & 5.66 & 4.50 & 4.35 & 0.20 & 0.841 \\
\hline DDCS [mm] & 5.93 & 5.10 & 4.64 & 4.13 & 2.80 & 4.14 & 1.88 & 0.060 \\
\hline $\mathrm{DHP}[\mathrm{mm}]$ & 2.37 & 1.70 & 2.09 & 3.02 & 2.80 & 2.25 & -1.01 & 0.311 \\
\hline AS [mm] & 4.82 & 4.50 & 2.29 & 5.47 & 4.90 & 3.43 & -0.39 & 0.696 \\
\hline \multicolumn{9}{|c|}{ Sitting position } \\
\hline CIT [degree] & 1.65 & 1.60 & 1.13 & 1.43 & 1.20 & 1.16 & 0.68 & 0.500 \\
\hline DHS [mm] & 4.62 & 3.90 & 4.47 & 4.80 & 3.30 & 4.61 & -0.20 & 0.841 \\
\hline DHCS $[\mathrm{mm}]$ & 5.77 & 5.00 & 4.22 & 4.52 & 4.50 & 3.98 & 1.07 & 0.285 \\
\hline DDCS [mm] & 5.79 & 4.65 & 4.41 & 6.59 & 6.80 & 4.54 & 0.63 & 0.531 \\
\hline $\mathrm{DHP}[\mathrm{mm}]$ & 2.71 & 2.20 & 2.26 & 3.79 & 3.30 & 3.10 & -1.12 & 0.261 \\
\hline AS $[\mathrm{mm}]$ & 6.46 & 6.10 & 3.02 & 6.60 & 5.60 & 3.43 & -0.15 & 0.882 \\
\hline
\end{tabular}

$n$ : number of observations; $\bar{x}$ : arithmetic mean; Me: median; SD: standard deviation; $t$ : result of Student's $t$-test for independent variables; $Z$ : result of Mann-Whitney $U$ test; $p$ : level of probability; CIT [degree]: coronal inclination of the trunk; DHS [mm]: difference in the heights of shoulders; DHCS [mm]: difference in the heights of the lower corners of the scapulae; DDCS [mm]: difference in the distances from the lower corners of the scapulae to the spine; DHP $[\mathrm{mm}]$ : difference in the height of the pelvis; SA [mm]: maximum deflection of the line connecting the spinous processes from C7-S1 line.

The findings show that, in comparison to the controls, the female preterm subjects presented with slightly higher values of parameters related to asymmetry in the inclination of trunk (CIT) and shoulders (DHS), as well as distance between the scapulae and the spine (DDCS), and with lower asymmetries in the height of the scapulae (DHCS) and the pelvis (DHP). The identified differences were statistically insignificant, both in standing and in sitting position (Table 3).

Analysis of data representing trunk posture parameters in boys showed mild differences between the groups related to asymmetry, regardless of the position during measurements. However, no statistically significant differences were identified in the parameters pertaining to body posture symmetry (Table 4).

In view of the lack of asymmetry related differences between the girls and the boys, relative to their birth time, the analyses of asymmetry orientation took into account only gestational age at birth.

The findings show that while standing the subjects in both groups more often present with lower position of the right shoulder, scapula and pelvis, the left scapula closer to the spine, and leftward deflection of spinous processes from C7S1 line. Similar tendencies are observed in sitting position, and both groups are also found with more frequent rightward inclination of the trunk while the preterm children, in the standing position, are more likely to present with leftward inclination of the trunk (Table 5).

\section{Discussion}

The present study has not identified statistically significant differences, in parameters defining postural symmetry, between preterm children and those born at term. Regardless of the birth time and position during measurement, subjects in the entire group more often present with lower position of the right shoulder, scapula and pelvis, the left scapula closer to the spine, and leftward deflection of spinous processes from C7-S1 line as well as rightward inclination of the trunk.

In the literature there are no reports related to parameters defining body posture in prematurely born children; researchers have previously focused only on assessing postural control or generally body posture in the relevant group. These studies, however, mainly relate to infants.

Findings of previous studies from 1986 report differences in postural control observed in infants. According to authors the number of atypical qualitative posture and mobility characteristics demonstrated by preterm infants was significantly greater than full-term infants ranging in age from 1 day to 9 months but not for those from 10 to 12 months of age. The predominant difference between the two samples was the presence of neck hyperextension and arching of the trunk which occurred significantly more often in the preterm infants [20]. De Vries and De Groot, in a study of dystonia in two-and-a-half-year-old premature infants and correctly born peers, reported lower rotational efficiency of the torso, as well as poorer hand and arm efficiency [21].

However, these differences are less distinctive in older children, closer in age to the group assessed in the present study. According to Kluenter et al., static and dynamic postural control did not significantly differ in full-term and preterm children, with very low birth weight, at 7 years of age [22].

Although, in statistical terms, the preterm infants presented a sequence in the development of postural control 
TABLE 4: Body posture parameters in standing and in sitting position, relative to gestational age at birth, in boys.

\begin{tabular}{|c|c|c|c|c|c|c|c|c|}
\hline \multirow[t]{2}{*}{ Variables } & \multicolumn{3}{|c|}{$\begin{array}{c}\text { Boys } \\
\text { preterm group }(n=25)\end{array}$} & \multicolumn{3}{|c|}{$\begin{array}{c}\text { Boys } \\
\text { control group }(n=22)\end{array}$} & \multirow[t]{2}{*}{$t / Z$} & \multirow[t]{2}{*}{$p$} \\
\hline & $\bar{x}$ & $\mathrm{Me}$ & $\mathrm{SD}$ & $\bar{x}$ & $\mathrm{Me}$ & SD & & \\
\hline \multicolumn{9}{|c|}{ Standing position } \\
\hline CIT [degree] & 1.24 & 0.90 & 0.97 & 1.44 & 1.25 & 0.84 & -1.05 & 0.295 \\
\hline DHS [mm] & 8.18 & 8.90 & 5.12 & 6.97 & 5.60 & 4.90 & 0.90 & 0.370 \\
\hline DHCS $[\mathrm{mm}]$ & 5.24 & 4.50 & 3.71 & 5.46 & 3.30 & 5.60 & 0.42 & 0.677 \\
\hline DDCS $[\mathrm{mm}]$ & 4.43 & 3.40 & 4.01 & 6.39 & 6.90 & 5.05 & -1.30 & 0.193 \\
\hline $\mathrm{DHP}[\mathrm{mm}]$ & 2.64 & 2.20 & 1.98 & 2.59 & 1.95 & 2.31 & 0.31 & 0.756 \\
\hline AS [mm] & 6.04 & 5.10 & 2.85 & 5.27 & 4.20 & 3.01 & 1.08 & 0.281 \\
\hline \multicolumn{9}{|c|}{ Sitting position } \\
\hline CIT [degree] & 1.62 & 1.45 & 1.14 & 1.80 & 1.60 & 1.18 & -0.37 & 0.715 \\
\hline DHS [mm] & 6.54 & 5.05 & 6.29 & 8.76 & 7.25 & 6.39 & -1.25 & 0.211 \\
\hline DHCS $[\mathrm{mm}]$ & 4.71 & 4.50 & 3.52 & 5.47 & 5.05 & 4.70 & -0.27 & 0.791 \\
\hline DDCS $[\mathrm{mm}]$ & 6.94 & 6.10 & 5.74 & 9.60 & 8.35 & 6.68 & -1.62 & 0.104 \\
\hline $\mathrm{DHP}[\mathrm{mm}]$ & 2.88 & 1.95 & 2.69 & 3.80 & 2.75 & 3.64 & -0.76 & 0.446 \\
\hline $\mathrm{AS}[\mathrm{mm}]$ & 7.46 & 7.60 & 3.04 & 7.58 & 6.35 & 5.03 & 0.63 & 0.529 \\
\hline
\end{tabular}

$n$ : number of observations; $\bar{x}$ : arithmetic mean; Me: median; SD: standard deviation; $t$ : result of Student's $t$-test for independent variables; $Z$ : result of Mann-Whitney $U$ test $p$ : level of probability; CIT [degree]: coronal inclination of the trunk; DHS [mm]: difference in the heights of shoulders; DHCS [mm]: difference in the heights of the lower corners of the scapulae; DDCS [mm]: difference in the distances from the lower corners of the scapulae to the spine; DHP $[\mathrm{mm}]$ : difference in the height of the pelvis; SA [mm]: maximum deflection of the line connecting the spinous processes from C7-S1 line.

similar to that of the full-term infants and were within the age range at each level showed by Pountney et al. for normal infants, they presented a different trend in the acquisition of motor abilities [23]. Pin et al. mention the differences in the movement behaviour of premature babies and peers born correctly. Uneven development of movement skills can be observed in different positions. [24].

According to De Groot et al. asymmetries in the motility and posture of preterm infants after term age are a common finding, but their diagnostic and prognostic significance has proved to be difficult to interpret. It has been claimed that if asymmetry is of central origin, then it should be most prominently detectable in infantile reactions that persist beyond the age when they should have disappeared [25]. What is more, Liu et al. point to the existence of structural asymmetry in the network of locomotor neurons and language networks. This asymmetry occurs in healthy preterm neonates at term equivalent age earlier than the development of speech and hand performance [26].

The preterm children had poorer muscle tone $[27,28]$. Posture and postural changes are ultimately the result of muscle activity. Postural muscle activation is generated before movement is initiated and involves constant change and accommodation. Adequate postural control and muscle tone are needed [29].

For the clinical study of posture, spontaneous and elicited behaviour which cause active muscle power (AMP) and passive muscle tone (PMT) should be examined. Preterm infants often have low PMT, but seem to develop exaggerated AMP. This behaviour is most obvious in the trunk and legs and has often been described as hyperextension in preterm infants after term age [30-32].
Despite the poorer muscle tone in preterm infants, the present study did not identify significantly greater postural asymmetries in preterm compared to full-term children.

In infants born preterm, immaturity of the system may lead to an asymmetrical performance and posture even when these infants are healthy [33-36]. A strong preference to turn the head to the right side and subtle asymmetries in fetal movements in infants born preterm have been described previously $[25,29,37-40]$. The high prevalence of a positional preference in infants born preterm at term equivalent age requires extra alertness to prevent the development of a deformational plagiocephaly, especially in boys and twins [41]. Yet, as it was found in the present study, at a later developmental age differences in frequency of asymmetries tend to decrease, regardless of sex, which may be linked with reduced asymmetries resulting from early interventions administered to preterm infants if asymmetry is identified after birth [41].

Small asymmetries, up to $1 \mathrm{~cm}$, in the trunk region, identified by noninvasive assessments are considered to be rather common [42, 43]; therefore just like symmetry, slight asymmetry may be recognized as typical and normal in the structure of human body. In the present study the mean size of asymmetries did not exceed $8 \mathrm{~mm}$. Yet, a continued tendency to tilt the body towards one side, in challenging conditions, such as pubertal growth spurt, may lead to increased asymmetry [42]. Premature birth does not predispose to greater asymmetries or their orientation; therefore these authors believe the factor can be disregarded in qualification for comparative screening studies. The identified tendency in asymmetry orientation makes it possible to prevent pathologic asymmetry. 


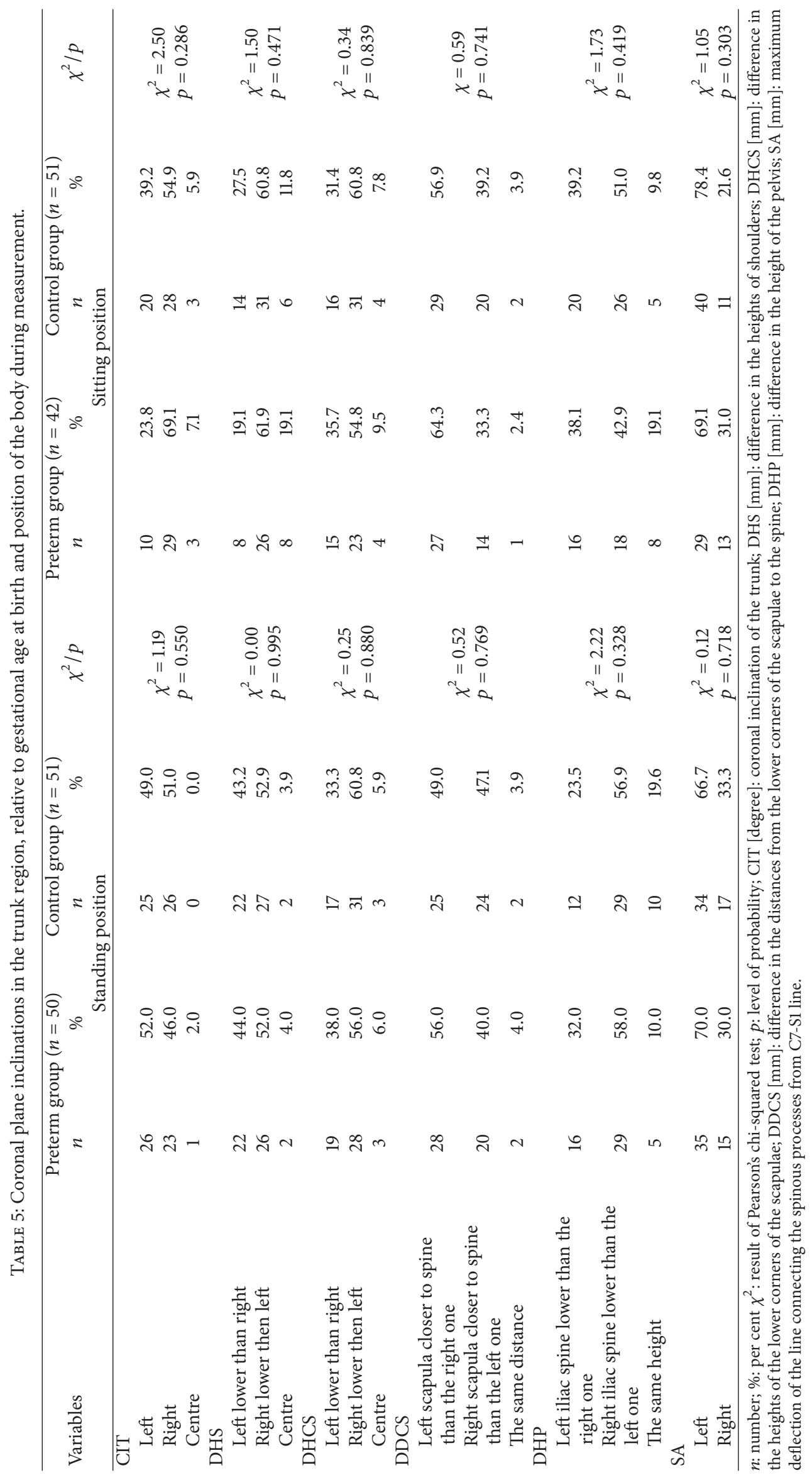


The presented study is the first detailed assessment of body posture in preterm children reported in the literature. Moreover, the study was carried out among subjects at six years of age, with measurements in standing and sitting position and with analysis of asymmetry orientation. Of significance here is also the inclusion criterion qualifying children born at gestational age of up to 32 weeks.

4.1. Limitations. A limitation of the study relates to the lack of analysis relative to the degree of prematurity at birth and size of asymmetry, yet this was not taken into account due to the fact that the results do not show statistical significance. Given the scarcity of the related evidence, similar research, however, should be continued taking into account the relationship between asymmetry and other factors, such as age, level of motor activity, sex, and degree of pathological asymmetry. Additionally it would be worthwhile to compare results between standing and sitting position, because examination of the surface morphology of the trunk in the sitting position is performed when a leg length inequality is present, in order to reveal true asymmetry and not the one which comes from tilting of the body in the standing position. Such analyses have not been conducted in the present study as no leg length asymmetries were identified among the participants.

Assessment designed in this way would identify not only relationship of asymmetry to age or motor activity, but also the correlation between the size of asymmetry and the relevant factors.

\section{Conclusions}

(1) There are no significant differences in body posture in the coronal plane, between preterm children and full-term children.

(2) Premature birth does not have adverse effects related to body posture asymmetry in preterm children at the age of six.

\section{Conflicts of Interest}

The authors have no conflicts of interest.

\section{Acknowledgments}

The authors would like to thank all the parents and children for their participation.

\section{References}

[1] N. Younge, R. F. Goldstein, C. M. Bann et al., "Survival and neurodevelopmental outcomes among periviable infants," The New England Journal of Medicine, vol. 376, no. 7, pp. 617-628, 2017.

[2] J. Schmidhauser, J. Caflisch, V. Rousson, H. U. Bucher, R. H. Largo, and B. Latal, "Impaired motor performance and movement quality in very-low-birthweight children at 6 years of age," Developmental Medicine \& Child Neurology, vol. 48, no. 9, pp. 718-722, 2006.
[3] D. Kernell, "The final common pathway in postural controldevelopmental perspective," Neuroscience \& Biobehavioral Reviews, vol. 22, no. 4, pp. 479-484, 1998.

[4] J. F. Samsom, L. De Groot, P. Dick Bezemer, H. N. Lafeber, and W. P. F. Fetter, "Muscle power development during the first year of life predicts neuromotor behaviour at 7 years in preterm born high-risk infants," Early Human Development, vol. 68, no. 2, pp. 103-118, 2002.

[5] K. A. Waitzman, "The importance of positioning the near-term infant for sleep, play, and development," Newborn and Infant Nursing Reviews, vol. 7, no. 2, pp. 76-81, 2007.

[6] S. Aucott, P. K. Donohue, E. Atkins, and M. C. Allen, "Neurodevelopmental care in the NICU," Mental Retardation and Developmental Disabilities Research Reviews, vol. 8, no. 4, pp. 298-308, 2002.

[7] L. C. Van Balen, L. J. Dijkstra, and M. Hadders-Algra, "Development of postural adjustments during reaching in typically developing infants from 4 to 18 months," Experimental Brain Research, vol. 220, no. 2, pp. 109-119, 2012.

[8] S. Hill, S. Engle, J. Jorgensen, A. Kralik, and K. Whitman, "Effects of facilitated tucking during routine care of infants born preterm," Pediatric Physical Therapy, vol. 17, no. 2, pp. 158-163, 2005.

[9] J. F. Samsom and L. De Groot, "The influence of postural control on motility and hand function in a group of 'high risk' preterm infants at 1 year of age," Early Human Development, vol. 60, no. 2, pp. 101-113, 2000.

[10] J. Skolimowskil, K. Barczyk, K. Dudek, B. Skolimowska, E. Demczuk-Włodarczyk, and J. Anwajler, "Posture in people with shoulder impingement syndrome," Ortopedia Traumatologia Rehabilitacja, vol. 9, no. 5, pp. 484-498, 2007.

[11] F. Berryman, P. Pynsent, J. Fairbank, and S. Disney, "A new system for measuring three-dimensional back shape in scoliosis," European Spine Journal, vol. 17, no. 5, pp. 663-672, 2008.

[12] N. D. Scutt, P. H. Dangerfield, and J. C. Dorgan, “The relationship between surface and radiological deformity in adolescent idiopathic scoliosis: effect of change in body position," European Spine Journal, vol. 5, no. 2, pp. 85-90, 1996.

[13] K. R. Saad, A. S. Colombo, and S. M. Amado João, "Reliability and validity of the photogrammetry for scoliosis evaluation: a cross-sectional prospective study," Journal of Manipulative and Physiological Therapeutics, vol. 32, no. 6, pp. 423-430, 2009.

[14] F. Porto, J. L. Gurgel, T. Russomano, and P. D. T. V. Farinatti, "Moiré topography: characteristics and clinical application," Gait \& Posture, vol. 32, no. 3, pp. 422-424, 2010.

[15] M. Mrozkowiak and M. Strzecha, "Projection moiré as a modern tool for diagnosis of body posture," Antropomotoryka, vol. 22, no. 60, pp. 33-49, 2012 (Polish).

[16] K. R. Saad, A. S. Colombo, A. P. Ribeiro, and S. M. A. João, "Reliability of photogrammetry in the evaluation of the postural aspects of individuals with structural scoliosis," Journal of Bodywork and Movement Therapies, vol. 16, no. 2, pp. 210-216, 2012.

[17] K. Walicka-Cupryś, R. Skalska-Izdebska, J. Drzał-Grabiec, and A. Sołek, "Correlation between body posture and postural stability of school children," Advances in Rehabilitation, vol. 27, no. 4, pp. 47-54, 2013.

[18] T. B. Grivas, E. S. Vasiliadis, G. Koufopoulos, D. Segos, G. Triantafyllopoulos, and V. Mouzakis, "Study of trunk asymmetry in normal children and adolescents," Scoliosis, vol. 1, no. 1, article 19, 2006. 
[19] J. Drzał-Grabiec, S. Snela, J. Rykała, J. Podgórska, and A. Banaś, "Changes in the body posture of women occurring with age," BMC Geriatrics, vol. 13, no. 1, article 108, 2013.

[20] J. Valvano and G. A. Degangi, "Atypical posture and movement findings in high-risk pre-term infants," Physical \& Occupational Therapy in Geriatrics, vol. 6, no. 2, pp. 71-85, 1986.

[21] A. M. De Vries and L. De Groot, "transient dystonias revisited: a comparative study of preterm and term children at $2 ;$ years of age," Developmental Medicine \& Child Neurology, vol. 44, no. 9, pp. 415-421, 2002.

[22] H. Kluenter, D. Roedder, A. Kribs, O. Fricke, B. Roth, and O. Guntinas-Lichius, "Postural control at 7 years of age after preterm birth with very low birth weight," Otology \& Neurotology, vol. 29, no. 8, pp. 1171-1175, 2008.

[23] T. E. Pountney, C. Mulcahy, and E. Green, "Early development of postural control," Physiotherapy, vol. 76, no. 12, pp. 799-802, 1990.

[24] T. W. Pin, T. Darrer, B. Eldridge, and M. P. Galea, "Motor development from 4 to 8 months corrected age in infants born at or less than 29 weeks' gestation," Developmental Medicine \& Child Neurology, vol. 51, no. 9, pp. 739-745, 2009.

[25] L. De Groot, B. Hopkins, and B. Touwen, "Motor asymmetries in preterm infants at 18 weeks corrected age and outcomes at 1 year," Early Human Development, vol. 48, no. 1-2, pp. 35-46, 1997.

[26] Y. Liu, D. Balériaux, M. Kavec et al., "Structural asymmetries in motor and language networks in a population of healthy preterm neonates at term equivalent age: a diffusion tensor imaging and probabilistic tractography study," NeuroImage, vol. 51, no. 2, pp. 783-788, 2010.

[27] M. Forslund and I. Bjerre, "Follow-up of preterm children I. Neurological assessment at 4 years of age," Early Human Development, vol. 20, no. 1, pp. 45-66, 1989.

[28] L. D. C. Magalhães, P. W. Catarina, V. M. Barbosa, M. C. Mancini, and M. L. Paixão, "A comparative study of the perceptual and motor performance at school age of preterm and full term children," Arquivos de Neuro-Psiquiatria, vol. 61, no. 2 A, pp. 250-255, 2003.

[29] L. De Groot, "Posture and motility in preterm infants," Developmental Medicine \& Child Neurology, vol. 42, no. 1, pp. 65-68, 2000.

[30] M. K. Georgieff, J. C. Bernbaum, M. Hoffman-Williamson, and A. Daft, "Abnormal truncal muscle tone as a useful early marker for developmental delay in low birth weight infants," Pediatrics, vol. 27, no. 5, pp. 659-663, 1986.

[31] M. Forslund and I. Bjerre, "Neurological assessment of preterm infants at term conceptional age in comparison with normal full-term infants," Early Human Development, vol. 8, no. 3-4, pp. 195-208, 1983.

[32] L. De Groot, B. Hopkins, and B. C. L. Touwen, "A method to assess the development of muscle power in preterms after term age," Neuropediatrics, vol. 23, no. 4, pp. 172-179, 1992.

[33] D. Ricci, D. M. M. Romeo, L. Haataja et al., "Neurological examination of preterm infants at term equivalent age," Early Human Development, vol. 84, no. 11, pp. 751-761, 2008.

[34] M. Pia Bucci, M. Tringali, C. Trousson, I. Husson, O. Baud, and V. Biran, "Spatial and temporal postural analysis in children born prematurely," Gait \& Posture, vol. 57, pp. 230-235, 2017.

[35] T.-N. Wang, T.-H. Howe, J. Hinojosa, and Y.-W. Hsu, "Postural control of pre-term infants at 6 and 12months corrected age," Early Human Development, vol. 86, no. 7, pp. 433-437, 2010.
[36] E. Mercuri, A. Guzzetta, S. Laroche et al., "Neurologic examination of preterm infants at term age: comparison with term infants," Journal of Pediatrics, vol. 142, no. 6, pp. 647-655, 2003.

[37] B. F. Fong, G. J. P. Savelsbergh, H. P. Van Geijn, and J. I. P. De Vries, "Does intra-uterine environment influence fetal head-position preference? A comparison between breech and cephalic presentation," Early Human Development, vol. 81, no. 6, pp. 507-517, 2005.

[38] J. J. Geerdink, B. Hopkins, and J. B. Hoeksma, “The development of head position preference in preterm infants beyond term age," Developmental Psychobiology, vol. 27, no. 3, pp. 153-168, 1994.

[39] J. I. P. de Vries, R. H. Wimmers, I. A. P. Ververs, B. Hopkins, G. J. P. Savelsbergh, and H. P. van Geijn, "Fetal handedness and head position preference: a developmental study," Developmental Psychobiology, vol. 39, no. 3, pp. 171-178, 2001.

[40] J. Nuysink, I. C. van Haastert, M. J. C. Eijsermans et al., "Prevalence and predictors of idiopathic asymmetry in infants born preterm," Early Human Development, vol. 88, no. 6, pp. 387-392, 2012.

[41] J. Nuysink, I. C. van Haastert, M. J. C. Eijsermans et al., "Prevalence and predictors of idiopathic asymmetry in infants born preterm," Early Human Development, vol. 88, no. 6, pp. 387-392, 2012.

[42] M. Vercauteren, M. Van Beneden, R. Verplaetse, P. H. Croene, D. Uyttendaele, and R. Verdonk, "Trunk asymmetries in a belgian school population," The Spine Journal, vol. 7, no. 6, pp. 555-562, 1982.

[43] S. Oyama, J. B. Myers, C. A. Wassinger, R. D. Ricci, and S. M. Lephart, "Asymmetric resting scapular posture in healthy overhead athletes," Journal of Athletic Training, vol. 43, no. 6, pp. 565-570, 2008. 


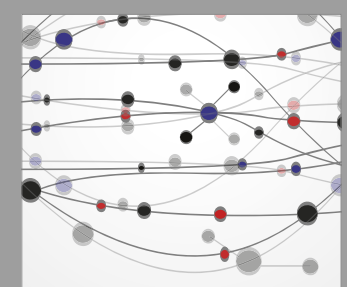

The Scientific World Journal
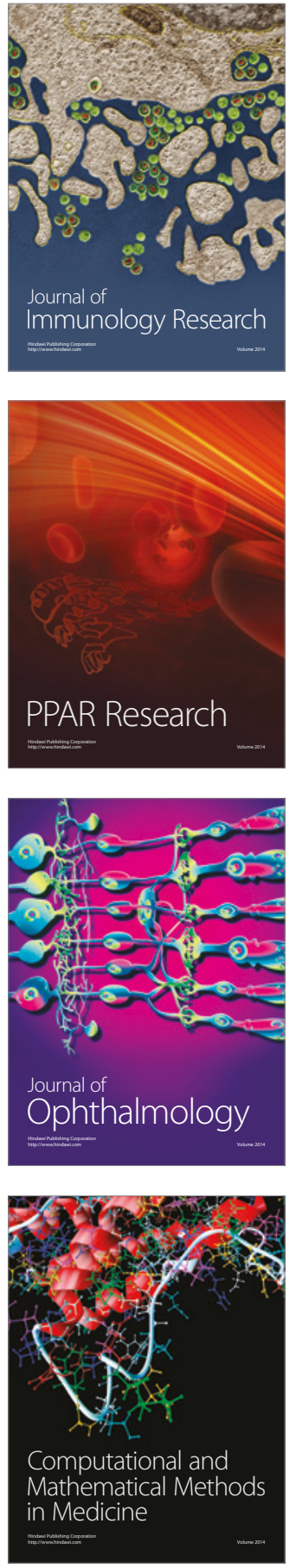

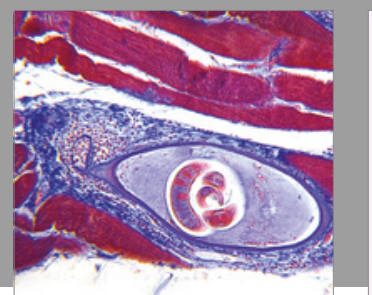

Gastroenterology Research and Practice
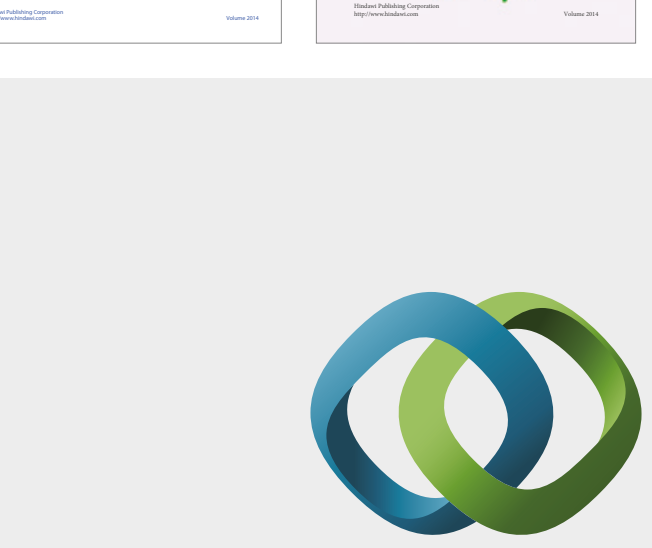

\section{Hindawi}

Submit your manuscripts at

https://www.hindawi.com
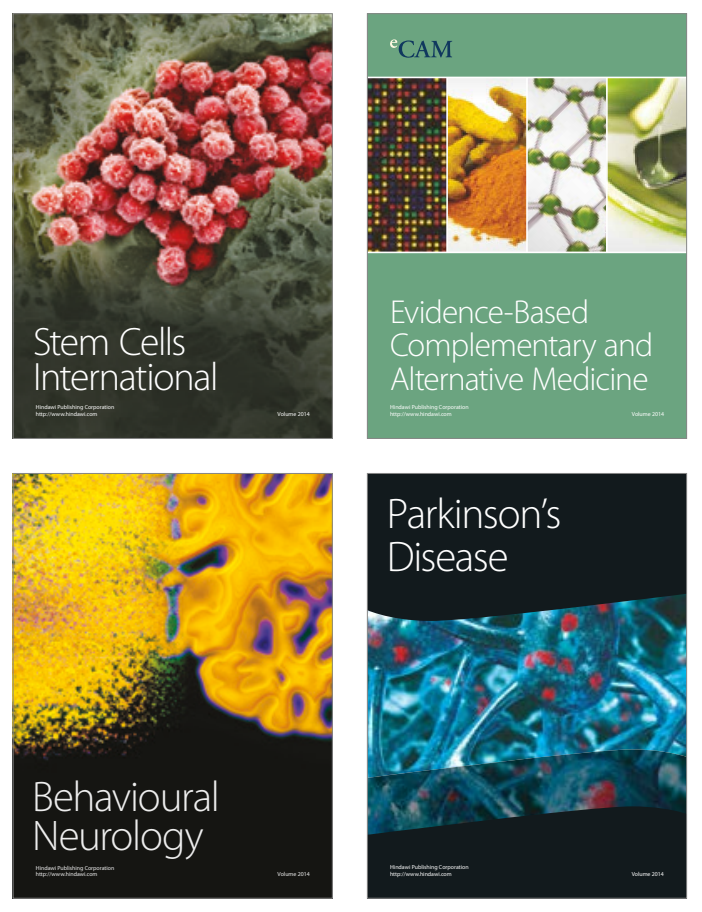
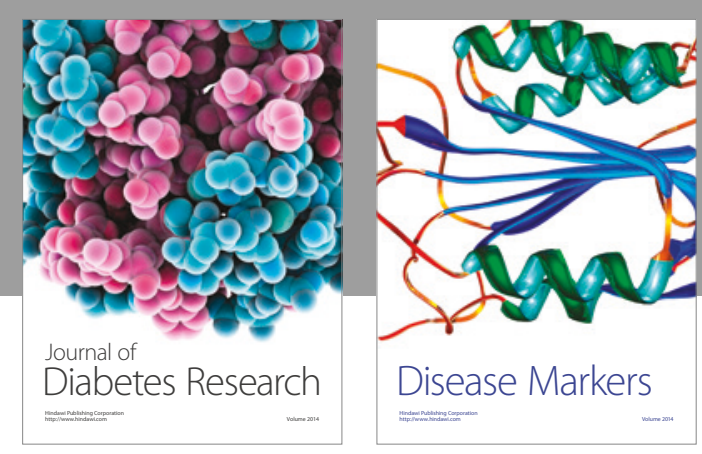

Disease Markers
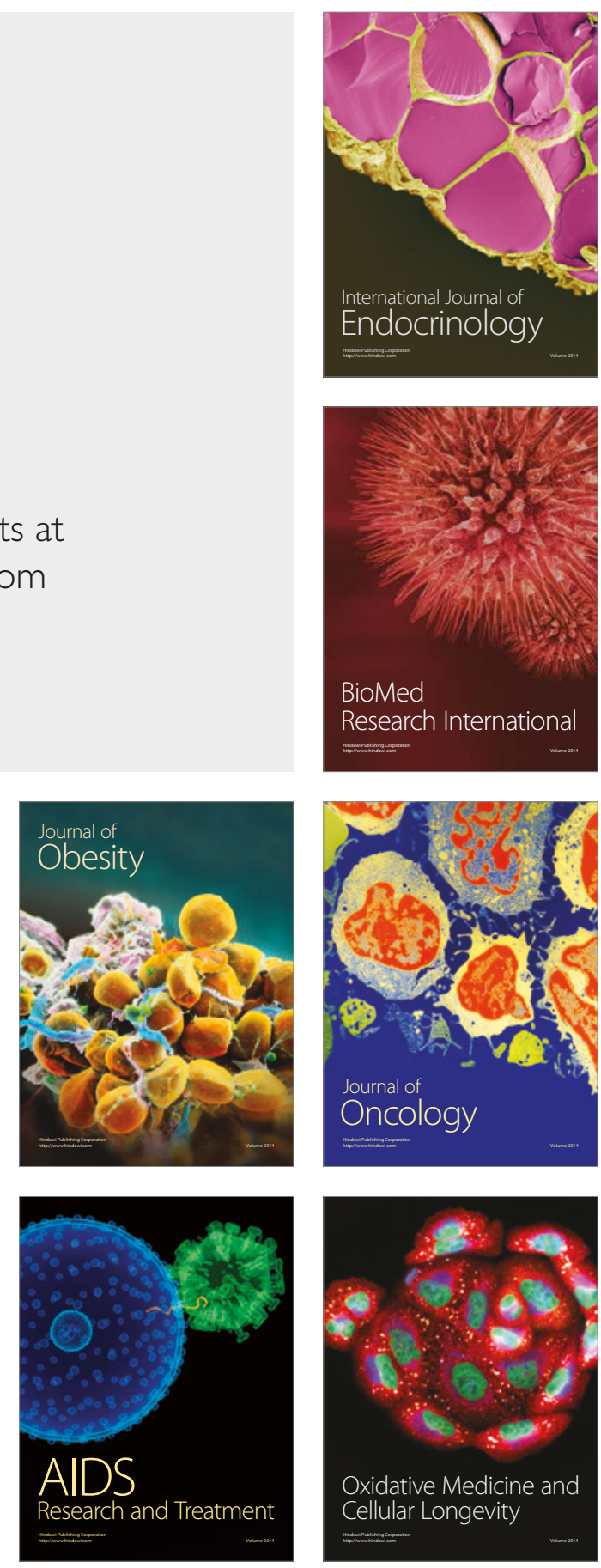